\title{
COMMENTARY
}

\section{Missing link or not, mobilise against delirium}

\author{
Valerie J Page ${ }^{*}$ and Annalisa Casarin \\ See related research by Abelha et al., http://ccforum.com/content/17/5/R257
}

\begin{abstract}
Delirium is known to be a predictor of adverse outcomes. In a prospective study Abelha and colleagues showed that postoperative delirium was an independent risk factor for deterioration in functional capacity following discharge. While evidence for causality remains elusive, there is no doubt that patients who develop delirium are left with new functional and cognitive impairment. Finding a pharmacological treatment for the prevention and treatment of delirium is a priority in delirium research and the results of ongoing trials are awaited. Early mobilisation of ICU patients has been demonstrated to decrease delirium and improve functional outcomes. Resources should be directed to appropriate, progressive mobilisation of all critically ill patients as a priority.
\end{abstract}

Abelha and colleagues explored the quality of life for postoperative patients surviving an ICU admission as a secondary outcome, showing that patients who develop delirium take longer to return to premorbid functionality with perceived quality of life worsening as dependency increases [1]. The authors were able to assess functional capacity before ICU admission in order to accurately determine any deterioration. Unsurprisingly, patients who subsequently developed delirium were more likely to be dependent with regard to at least one activity before surgery. This is a relatively large critical care study with a total of 562 patients, although the average Acute Physiology and Chronic Health Evaluation score was 8 and only 89 patients developed delirium. The risk of functional deterioration would be expected to be even higher in a sicker patient population admitted acutely to a general mixed ICU.

This finding is consistent with the results of a large multicentre cognitive outcome trial establishing that,

\footnotetext{
* Correspondence: Valerie.Page@whht.nhs.uk

Intensive Care Unit, Watford General Hospital, Vicarage Road, Watford WD18 $9 \mathrm{HB}, \mathrm{UK}$
}

after critical illness, patients are left with new and clinically important cognitive impairment linked to duration of delirium [2]. There is an ever-increasing body of scientifically robust evidence regarding critically ill patients, delirium and outcomes [3]. Animal studies support the hypothesis that delirium in a vulnerable patient is a key determinant rather than a predictor of adverse outcomes $[4,5]$. There is clearly an association between developing delirium and adverse outcomes, in this case functional status, although causality is yet to be established - the missing link.

The return rate of follow-up questionnaires was 73\%; the authors point out that nonresponders were more likely to have a different type of anaesthesia, lower temperature on return to surgical ICU and red cell transfusion [1]. Noone would suggest that keeping patients warmer would make them more likely to return a follow-up form; this is illustrative because some intensivists consider delirium in the same light as temperature - that is, as a sign, not itself something to be targeted to improve outcomes. The missing link enables negative opinions ranging from delirium being no more than an epiphenomenon through to pessimism that anything can be done to modify delirium.

So is it possible to modify delirium, prevent delirium or decrease the duration or severity? As critical care clinicians we look to drugs as the most feasible intervention in our very dependent debilitated and delirious patient population. However, the findings of a recent randomised controlled trial into whether early haloperidol can prevent or reduce delirium as opposed to placebo in mechanically ventilated patients did not support the drug's use [6]. More research is needed and additional studies exploring the use of antipsychotics and alternative targets for drug intervention (for example, neuroinflammation) are ongoing [7].

A study into early mobilisation demonstrated that $59 \%$ of those patients who underwent a safe and well-tolerated programme of physiotherapy from admission returned to independent functional status, as opposed to $35 \%$ of those undergoing standard care [8]. The intervention group had 
a shorter duration of delirium. This is an area for improvement in the majority of ICUs where resources are limited by investment in practitioners, time and working practices. In 2008 a UK study found that approximately $25 \%$ of patients were not mobilised on any given day because of shortage of physiotherapy staff or because it was a weekend [9]. This observation is supported by an updated systematic review into physiotherapy in intensive care, which concludes with the suggestion that early progressive mobilisation should be implemented as a matter of priority in all adult ICUs and as an area of clinical focus for ICU physiotherapists [10].

Bearing in mind the outcomes impacting on quality of life that many of our patients are left to manage in the short term or for the rest of their lives, delirium cannot be ignored. In units such as our own where delirium is monitored on a daily basis, we see hypoactive delirium holding up patients' clinical progress. At the very least, this tells us we have not treated the underlying cause. Why wait when we can make a difference today? Let us get our patients moving on course to a better quality of life. Independent activities of daily living are the least we want for our patients, to be continent, to wash and to be able to eat a meal without assistance.

\section{Competing interests}

The authors declare that they have no competing interests.

Published: 31 Jan 2014

\section{References}

1. Abelha F, Luís C, Veiga D, Parente D, Fernandes V, Santos P, Botelho M, Santos A, Santos C: Outcome and quality of life in patients with postoperative delirium during an ICU stay following major surgery. Crit Care 2013, 17:R257.

2. Pandharipande PP, Girard TD, Jackson JC, Morandi A, Thompson JL, Pun BT, Brummel NE, Hughes CG, Vasilevskis EE, Shintani AK, Moons KG, Geevarghese SK, Canonico A, Hopkins RO, Bernard GR, Dittus RS, Ely EW: Long-term cognitive impairment after critical illness. N Engl J Med 2013, 369:1306-1316.

3. Zhang Z, Pan L, Ni H: Impact of delirium on clinical outcome in critically ill patients: a meta-analysis. Gen Hosp Psychiatry 2013, 5:105-111.

4. Field RH, Gossen A, Cunningham C: Prior pathology in the basal forebrain cholinergic system predisposes to inflammation induced working memory deficits: reconciling inflammatory and cholinergic hypotheses of delirium. J Neurosci 2012, 32:6288-6294.

5. Griffin EW, Skelly DT, Murray CL, Cunningham C: Cyclooxygenase-1dependent prostaglandins mediate susceptibility to systemic inflammation-induced acute cognitive dysfunction. J Neurosci 2013, 33:15248-15258.

6. Page VJ, Ely EW, Gates S, Zhao XB, Alce T, Shintani A, Jackson J, Perkins GD, McAuley DF: Effect of intravenous haloperidol on the duration of delirium and coma in critically ill patients (Hope-ICU): a randomised, double-blind, placebo-controlled trial. Lancet Respir Med 2013, 1:15-23.

7. Morandi A, Hughes CG, Girard TD, McAuley DF, Ely EW, Pandharipande PP: Statins and brain dysfunction: a hypothesis to reduce the burden of cognitive impairment in patients who are critically ill. Chest 2011, 140:580-585.

8. Schweickert WD, Pohlman MC, Pohlman AS, Nigos C, Pawlik AJ, Esbrook CL, Spears L, Miller M, Franczyk M, Deprizio D, Schmidt GA, Bowman A, Barr R, McCallister KE, Hall JB, Kress JP: Early physical and occupational therapy in mechanically ventilated, critically ill patients: a randomised controlled trial. Lancet 2009, 373:1874-1882

9. McWilliams DJ, Pantelides KP: Does physiotherapy led early mobilisation affect length of stay on ICU? Respir Care J 2008, 40:5-11.

10. Stiller K: Physiotherapy in intensive care: an updated systematic review. Chest 2013, 144:825-847.

10.1186/cc13712

Cite this article as: Page and Casarin: Missing link or not, mobilise against delirium. Critical Care 2014, 18:105 